\title{
Crescimento e níveis de solutos orgânicos e inorgânicos em cultivares de Vigna unguiculata submetidos à salinidade
}

\author{
PAULO HENRIQUE A. COSTA ${ }^{1}$, JOSÉ V. SILVA ${ }^{1}$, MARLOS A. BEZERRA ${ }^{2}$, \\ JOAQUIM ENÉAS FILHO ${ }^{1}$, JOSÉ T. PRISCO ${ }^{1}$ e ENÉAS GOMES FILHO ${ }^{1,3}$
}

(recebido: 27 de junho de 2002; aceito: 7 de maio de 2003)

\begin{abstract}
Growth and organic and inorganic solute contents in $\mathrm{NaCl}$-stressed cultivars of Vigna unguiculata). The effects of $\mathrm{NaCl}$-salinity on growth and on organic and inorganic solute contents were analyzed in seven cowpea cultivars grown in a greenhouse. The test plants were cultivated in a nutrient solution in which at day 14 after sowing $\mathrm{NaCl}$ was added for three consecutive days in $25 \mathrm{mM}$ concentration to a total of $75 \mathrm{mM}$. Control plants remained in the nutrient solution and harvesting was done at day 33. Salt stress reduced the dry mass of all cultivars, however the Pitiúba and Vita 5 were the most tolerant whereas TVU the most sensible. Leaf suculence and the sclerose index correlated well with the salt tolerance degree but increased significantly with the increasing salt concentration only in the most tolerant cultivars. By contrast, root/shoot dry mass increased only in the less tolerant cultivars. Overall, shoot content of both $\mathrm{Na}^{+}$and $\mathrm{Cl}^{-}$increased in response to salinity but accumulated drastically only in the more sensible cultivars, particularly in TVU. In leaves, $\mathrm{K}^{+}$content was higher than $\mathrm{Na}^{+}$ and $\mathrm{Cl}^{-}$contents but none of there were significantly affected by the salt stress. Consequently the $\mathrm{Na}^{+} / \mathrm{K}^{+}$ratio was higher in the most sensible cultivars. This may represent an important factor for the growth reduction observed in the stressed plants. With regard to proline, soluble carbohydrate and $\mathrm{N}$-amino solutes were not related among their contents and the degree of $\mathrm{NaCl}$ tolerance in the cultivars used in the study.
\end{abstract}

Key words - growth, organic and inorganic solutes, salinity, Vigna unguiculata

RESUMO - (Crescimento e níveis de solutos orgânicos e inorgânicos em cultivares de Vigna unguiculata submetidos à salinidade). Os efeitos da salinidade no crescimento e nos teores de solutos orgânicos e inorgânicos foram analisados em sete cultivares de Vigna unguiculata. As plantas foram cultivadas em solução nutritiva sem $\mathrm{NaCl}$ (controle) e com $\mathrm{NaCl}$ a $75 \mathrm{mM}$ (estresse salino), em casa de vegetação. Após 14 dias da semeadura, adicionou-se $25 \mathrm{mM}$ de sal diariamente, durante três dias, perfazendo o total de $75 \mathrm{mM}$. A coleta foi realizada no 33을. A salinidade reduziu a matéria seca de todos os cultivares, sendo Pitiúba e Vita 5 os menos afetados e TVU o que sofreu maior redução. A suculência foliar e o índice de esclerofilia foram concordantes com o grau de tolerância, aumentando significativamente, em função da salinidade, apenas nos cultivares com menores reduções nas matérias secas. Contrariamente, a relação raiz/parte aérea teve maior aumento nos cultivares mais afetados. Os teores de $\mathrm{Na}^{+} \mathrm{e} \mathrm{Cl}-$ foliares aumentaram em resposta ao estresse salino, sendo o $\mathrm{Na}^{+}$acumulado em níveis maiores nos cultivares mais afetados, especialmente no TVU. Os níveis de $\mathrm{K}^{+}$foliar, que se mostraram mais elevados que os de $\mathrm{Na}^{+} \mathrm{e}$ $\mathrm{Cl}^{-}$, foram poucos afetados pela salinidade, de modo que a relação $\mathrm{Na}^{+} / \mathrm{K}^{+}$aumentou mais nos cultivares mais afetados e, possivelmente, se constituiu num fator importante para a maior redução em seus crescimentos. As variações nos teores de prolina, carboidratos solúveis e $\mathrm{N}$-aminossolúveis em resposta à salinidade indicam uma falta de proporcionalidade entre seus níveis e o grau de tolerância à salinidade nos cultivares de feijão-de-corda estudados.

Palavras-chave - crescimento, salinidade, solutos orgânicos e inorgânicos, Vigna unguiculata

\section{Introdução}

A salinidade é um problema que atinge cerca de 45 dos 230 milhões de hectares da área irrigada do globo terrestre, trazendo sérios prejuízos para a produção agrícola, principalmente nas regiões áridas e semi-

\footnotetext{
1. Universidade Federal do Ceará, Centro de Ciências, Departamento de Bioquímica e Biologia Molecular, Laboratório de Fisiologia Vegetal, Caixa Postal 6039, 60455-900 Fortaleza, CE, Brasil.

2. Embrapa Agroindústria Tropical, Caixa Postal 3761, 60511-110 Fortaleza, CE, Brasil.

3. Autor para correspondência: egomesf@ufc.br
}

áridas, onde cerca de $25 \%$ da área irrigada já se encontra salinizada (FAO 2000). As concentrações de sais que restringem o crescimento da planta variam amplamente entre as espécies, e dependem não apenas do tipo de sal, mas do tempo de exposição e de seu estádio de desenvolvimento (Shannon 1992). Enquanto as halófitas são capazes de crescer em solos com concentrações de sais de até $20 \%$, as glicófitas, em que se encontram a maioria das plantas cultivadas, têm seus crescimentos inibidos em concentrações da ordem de $0,3 \%$ a $0,5 \%$ (Levitt 1980 ). Acredita-se que, em estresses de curta duração, predominem os efeitos osmóticos dos sais, fazendo com que o potencial hídrico 
do ambiente radicular diminua e restrinja a absorção de água; em estresses de longa duração, todavia, os íons se acumulam e provocam toxidez, induzindo distúrbios nutricionais e metabólicos (Munns 2002).

Segundo O'Leary (1995), as plantas halotolerantes podem se adaptar aos altos níveis de sais, restringindo a entrada dos íons nas raízes, ou impedindo-os de chegarem às folhas através do xilema, ou sequestrando no vacúolo os íons que chegam às folhas quando a absorção e o transporte dos íons não são impedidos. $\mathrm{O}$ objetivo final desses mecanismos de tolerância é manter uma concentração citosólica de sódio relativamente baixa e uma alta relação $\mathrm{K}^{+} / \mathrm{Na}^{+}$(Niu et al. 1995). Para manter a absorção de água em condições de estresse osmótico, muitas plantas acumulam solutos orgânicos no citosol e/ou íons inorgânicos no vacúolo, os quais baixam o potencial osmótico, num mecanismo conhecido como ajustamento osmótico (Hopkins 1999). Esses solutos orgânicos, na maioria, são álcoois, carboidratos solúveis, $\mathrm{N}$-aminossolúveis, sais de amônio quaternários e sais sulfônicos terciários (Rodhes \& Hanson 1993, Trossat et al. 1998); acredita-se também que possam contribuir para a estabilidade das proteínas e das membranas celulares, além de exercerem efeitos protetores contra radicais livres de oxigênio (Greenway \& Munns 1980, Bohnert \& Shen 1999). Entre os $\mathrm{N}$-aminossolúveis que se acumulam em resposta ao estresse osmótico, a prolina é indiscutivelmente a mais relatada. No entanto, há autores que sugerem que o acúmulo de prolina é apenas uma consequência do estresse e não uma resposta adaptativa. Liu \& Zhu (1997), utilizando mutantes sos 1 de Arabidopsis thaliana sensíveis ao estresse salino, observaram que estes acumulavam mais prolina que os tipos selvagens (tolerantes). O fato é que, além de não se ter uma visão clara das plantas que se ajustam osmoticamente produzindo solutos orgânicos, também pouco se conhece sobre que tipo específico de soluto é acumulado por uma determinada espécie.

A seleção de genótipos tolerantes à salinidade, por meio de melhoramento genético clássico, não tem produzido os efeitos desejados por falta de conhecimentos sobre os mecanismos fisiológicos e bioquímicos envolvidos com o processo de adaptação das plantas ao estresse (Noble \& Rogers 1992). Atualmente, mediante a tecnologia do DNA recombinante, é possível conseguir-se plantas transgênicas que sejam tolerantes à salinidade (Apse et al. 1999). Entretanto, isso só é viável com o conhecimento das etapas fisiológicas e bioquímicas envolvidas nos mecanismos de tolerância à salinidade.
Portanto, este trabalho foi concebido para avaliar os efeitos do estresse salino no crescimento e nos teores de alguns solutos orgânicos (prolina, carboidratos solúveis, $\mathrm{N}$-aminossolúveis e proteínas solúveis) e inorgânicos $\left(\mathrm{Cl}^{-}, \mathrm{Na}^{+}\right.$e $\left.\mathrm{K}^{+}\right)$de sete cultivares de feijãode-corda, de modo a contribuir para o entendimento da osmorregulação na tolerância aos sais nessa espécie, além de identificar os cultivares mais tolerantes ao estresse salino.

\section{Material e métodos}

As sementes de feijão-de-corda, Vigna unguiculata (L.) Walp., cultivares BR 10 Piauí, CE 670, Epace 10, Pitiúba, cultivadas largamente na região nordeste do Brasil, e TVU, Vita 3 e Vita 5, introduzidas pela Embrapa em trabalhos de resistência à seca, foram provenientes do Departamento de Fitotecnia da Universidade Federal do Ceará. As sementes, após tratamento por $5 \mathrm{~min}$ com uma solução de hipoclorito de sódio contendo cloro ativo a $0,75 \%$, foram semeadas entre duas folhas de papel de filtro umedecidas com água destilada (Prisco \& Vieira 1976) e deixadas por sete dias sob luz difusa, a $25 \pm 2{ }^{\circ} \mathrm{C}$ e umidade relativa próxima a $100 \%$. Em seguida, as plântulas foram transferidas para casa de vegetação e colocadas em meio hidropônico com solução nutritiva de Hoagland (Epstein 1975) diluída 1:4 (v:v), por sete dias. Após o período de adaptação, as plântulas foram selecionadas, transferidas para vasos plásticos contendo $6 \mathrm{~L}$ de solução nutritiva diluída 1:2 (v:v) e submetidas aos tratamentos controle (solução nutritiva) e salino (solução nutritiva contendo $\mathrm{NaCl}$ a $75 \mathrm{mM}$ ), cada um com três repetições. Essa concentração de $\mathrm{NaCl}$ foi estabelecida em experimentos preliminares. A adição de $\mathrm{NaCl}$ teve início no $14^{\circ}$ dia após a semeadura e foi feita em dias seguidos, na proporção de $25 \mathrm{mM}$ a cada dia, até completar $75 \mathrm{mM}$. As soluções nutritivas foram aeradas constantemente e o nível das mesmas nos vasos foi mantido pela adição de água destilada, sendo realizadas trocas das mesmas a cada sete dias. $\mathrm{O} \mathrm{pH}$ foi monitorado diariamente e mantido próximo a 5,5. Os valores de condutividade elétrica foram de $0,82 \mathrm{dS} \cdot \mathrm{m}^{-1}$ no tratamento controle e de $7,35 \mathrm{dS} . \mathrm{m}^{-1}$, no tratamento salino. As médias de temperatura e de umidade relativa do ar no interior da casa de vegetação foram de $29,5{ }^{\circ} \mathrm{C}$ e $71,4 \%$, respectivamente.

Aos 33 dias após a semeadura, as plantas foram coletadas e divididas em raiz e parte aérea, sendo efetuadas as medidas de área foliar, com um medidor de área (LI-3100, Li-Cor, Inc. Lincoln, NE, USA), e de matéria seca, que foi obtida pela pesagem do material em estufa a $65^{\circ} \mathrm{C}$ por dois dias. Com essas medidas, foram estimados os índices de esclerofilia (matéria seca/área foliar), bem como os valores da relação de matéria seca raiz/parte aérea. A suculência foliar (massa de água por área foliar), foi determinada na $4^{\mathrm{a}}$ folha definitiva a partir do ápice do ramo. A massa de água dessas 
folhas foi obtida pela diferença entre os valores das matérias fresca e seca.

As concentrações de íons inorgânicos foram determinadas nas folhas desenvolvidas e nas folhas em início de desenvolvimento (ápices de cada ramo das plantas). Para extração dos íons, $50 \mathrm{mg}$ do material vegetal liofilizado e macerado foram homogeneizados, por agitação, com $10 \mathrm{~mL}$ de água deionizada, a $25{ }^{\circ} \mathrm{C}$, por $1 \mathrm{~h}$. Em seguida, o homogenato foi filtrado em papel de filtro, sob vácuo. Os teores de $\mathrm{Na}^{+}$e $\mathrm{K}^{+}$foram determinados por fotometria de chama, segundo Malavolta et al. (1989), e os de $\mathrm{Cl}^{-}$, conforme Gaines et al. (1984), usando-se do reagente $\mathrm{Hg}(\mathrm{SCN})_{2}$ $\mathrm{Fe}\left(\mathrm{NO}_{3}\right)_{3}$, sendo feitas leituras de absorbância em $460 \mathrm{~nm}$, utilizando-se $\mathrm{NaCl}$ como padrão.

Para as determinações dos solutos orgânicos, foram coletadas extremidades de raízes $(\leq 1 \mathrm{~cm})$ e folhas em início de desenvolvimento, as quais foram liofilizadas e maceradas.

O extrato contendo a prolina livre foi preparado homogeneizando-se $5 \mathrm{~mL}$ de ácido sulfossalicílico a $3 \%$ com $20 \mathrm{mg}$ do material liofilizado, a $25^{\circ} \mathrm{C}$, por $1 \mathrm{~h}$, com agitações ocasionais. Em seguida, o homogenato foi centrifugado a 3.000 g por $5 \mathrm{~min}, \mathrm{a} 25^{\circ} \mathrm{C}$, recolhendo-se o sobrenadante para a determinação de prolina livre, por intermédio da reação com o reagente da ninhidrina ácida e leitura de absorbância a $520 \mathrm{~nm}$, usando-se como padrão a prolina (Bates et al. 1973).

Os carboidratos solúveis foram extraídos homogeneizando-se $2 \mathrm{mg}$ do material liofilizado com $4 \mathrm{~mL}$ de água destilada, por $1 \mathrm{~h}$, com agitações ocasionais, seguido de centrifugação a $3.000 \mathrm{~g}$ por $5 \mathrm{~min}$, a $25^{\circ} \mathrm{C}$. Em seguida, adicionou-se a uma alíquota do sobrenadante o reagente fenol-ácido sulfúrico, sendo os carboidratos quantificados a partir de leituras de absorbância em $490 \mathrm{~nm}$, usando-se como padrão a D-glicose (Dubois et al. 1956).

Os N-aminossolúveis foram extraídos homogeneizandose, por $1 \mathrm{~h}, 2 \mathrm{mg}$ do material liofilizado com $1 \mathrm{~mL}$ de tampão fosfato de sódio e potássio $0,01 \mathrm{M}, \mathrm{pH} 7,6$, contendo $\mathrm{NaCl} 0,1 \mathrm{M}$, sendo o homogenato centrifugado a $3.000 \mathrm{~g}$ por 5 min a $25{ }^{\circ} \mathrm{C}$. A uma alíquota do sobrenadante $(0,5 \mathrm{~mL})$ adicionou-se $0,5 \mathrm{~mL}$ de ácido tricloroacético a $10 \%$. Após $1 \mathrm{~h}$ de repouso, o material foi centrifugado a $12.000 \mathrm{~g}$ por $5 \mathrm{~min}$, a $25{ }^{\circ} \mathrm{C}$ e o sobrenadante utilizado para determinação de $\mathrm{N}$-aminossolúvel através da reação com a ninidrina, sendo feitas leituras de absorbância em $570 \mathrm{~nm}$, usando-se como padrão a leucina (Cocking \& Yemm 1954).

As proteínas solúveis foram quantificadas nos mesmos extratos utilizados para a determinação de $\mathrm{N}$-aminossolúveis, via reação com o reagente do Coomassie, sendo as leituras de absorbância feitas em $595 \mathrm{~nm}$, usando-se a albumina de soro bovino como padrão (Bradford 1976).

Tanto para os íons inorgânicos quanto para os solutos orgânicos, foram preparados três extratos, sendo cada um deles dosado em triplicata, exceto o $\mathrm{Na}^{+}$e o $\mathrm{K}^{+}$. Os resultados foram expressos em $\mu$ mol. $\mathrm{g}^{-1} \mathrm{MS}$.

$O$ delineamento experimental utilizado foi o inteiramente casualizado com arranjo fatorial $7 \times 2$, sendo o primeiro nível os cultivares utilizados e o segundo os níveis de sal. Os dados foram submetidos a análise de variância e as médias comparadas pelo teste de Tukey, a 5\% de probabilidade.

\section{Resultados}

A matéria seca das raízes das plantas dos cultivares de feijão-de-corda estudados, à exceção dos cultivares Pitiúba e Vita 5, diminuiu significativamente devido à salinidade (figura 1A). O cultivar TVU apresentou maior redução na matéria seca das raízes $(75,6 \%)$, enquanto os cultivares Epace 10, CE 670, BR 10 Piauí e Vita 3 apresentaram reduções próximas a 50\%. A matéria seca da parte área foi significativamente reduzida pela salinidade em todos os cultivares, sendo as maiores reduções observadas nos cultivares TVU $(82,0 \%)$ e CE 670 (76,0\%), e as menores, nos cultivares Pitiúba (42,3\%), Vita 5 (47,0\%), Epace 10 (50,2\%) e BR 10 Piauí (52,0\%) (figura 1B). Resultados semelhantes foram observados no que respeita à matéria seca total das plantas (figura 1C). A relação raiz/parte aérea foi significativamente aumentada pela salinidade nos cultivares TVU (35,6\%), Vita $5(43,0 \%)$, Vita 3 (72,6\%) e CE 670 (114,6\%), enquanto nos demais não houve alterações significativas (figura 1D).

A salinidade reduziu significativamente a área foliar de todos os cultivares estudados (figura 2A). TVU, CE 670 e Vita 3 foram os mais afetados pela salinidade, com reduções de $88,2 \%, 85,0 \%$ e $74,4 \%$, respectivamente, enquanto os cultivares Pitiúba e Vita 5 foram os menos afetados, com reduções em torno de $60,0 \%$. A salinidade aumentou significativamente o índice de esclerofilia nos cultivares Epace 10 (29,9\%), Pitiúba (41,0\%) e Vita 5 (66,6\%), enquanto nos demais não foram observadas diferenças significativas (figura 2B). A suculência foliar aumentou em função da salinidade de forma significativa apenas nos cultivares Vita 5 (35,0\%), Epace 10 (41,4\%) e Pitiúba $(53,8 \%)$ (figura $2 \mathrm{C})$.

A partir dos dados da análise de crescimento, os cultivares estudados foram agrupados em três níveis, de acordo com o grau de tolerância ao estresse salino (tabela 1). Com base na produção de matéria seca das raízes, os cultivares Pitiúba e Vita 5 foram os que, estatisticamente, sofreram menores reduções ou nenhuma (nível 1). Os cultivares Epace 10, CE 670, BR 10 Piauí e Vita 3 sofreram reduções intermediárias (nível 2) enquanto o TVU apresentou maior redução devido ao estresse salino (nível 3). Levando-se em conta as matérias secas da parte aérea e da planta, os cultivares Epace 10 e BR 10 Piauí ficaram, juntamente 

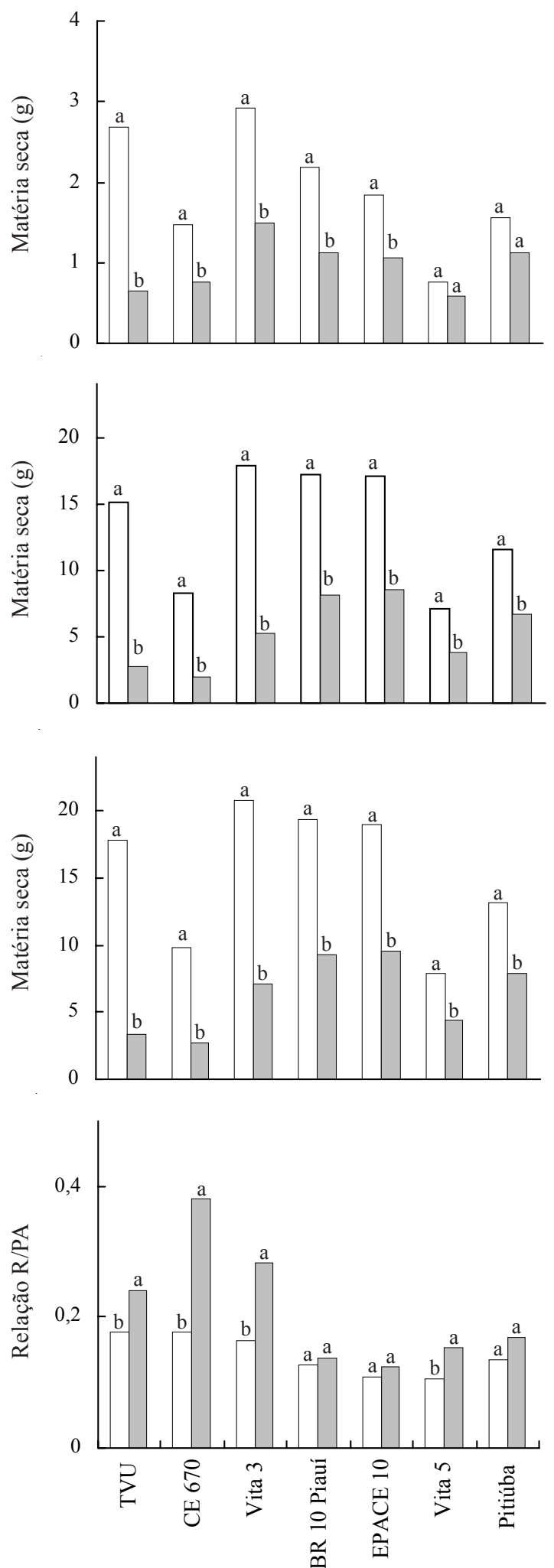

Figura 1. Matérias secas da raiz (A), parte aérea (B) e planta (C) e relação raiz/parte aérea (D) dos cultivares de feijãode-corda submetidos aos tratamentos-controle $(\square)$ e de estresse salino $(\square)$. Valores com mesmas letras dentro de cada cultivar não diferem entre si pelo teste de Tukey, a 5\% de probabilidade.

B

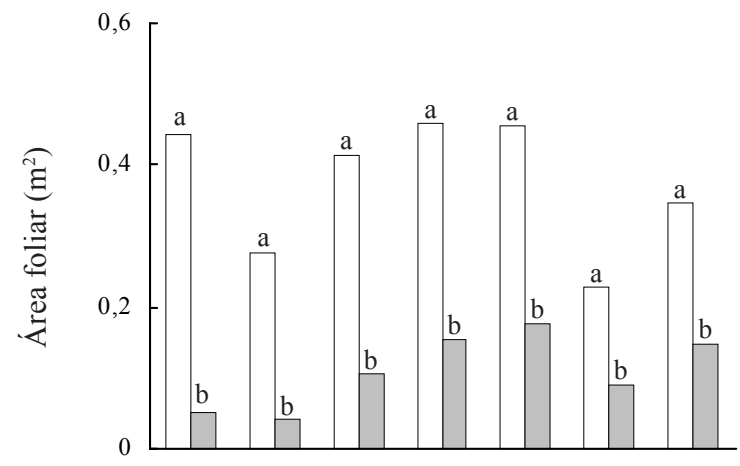

A
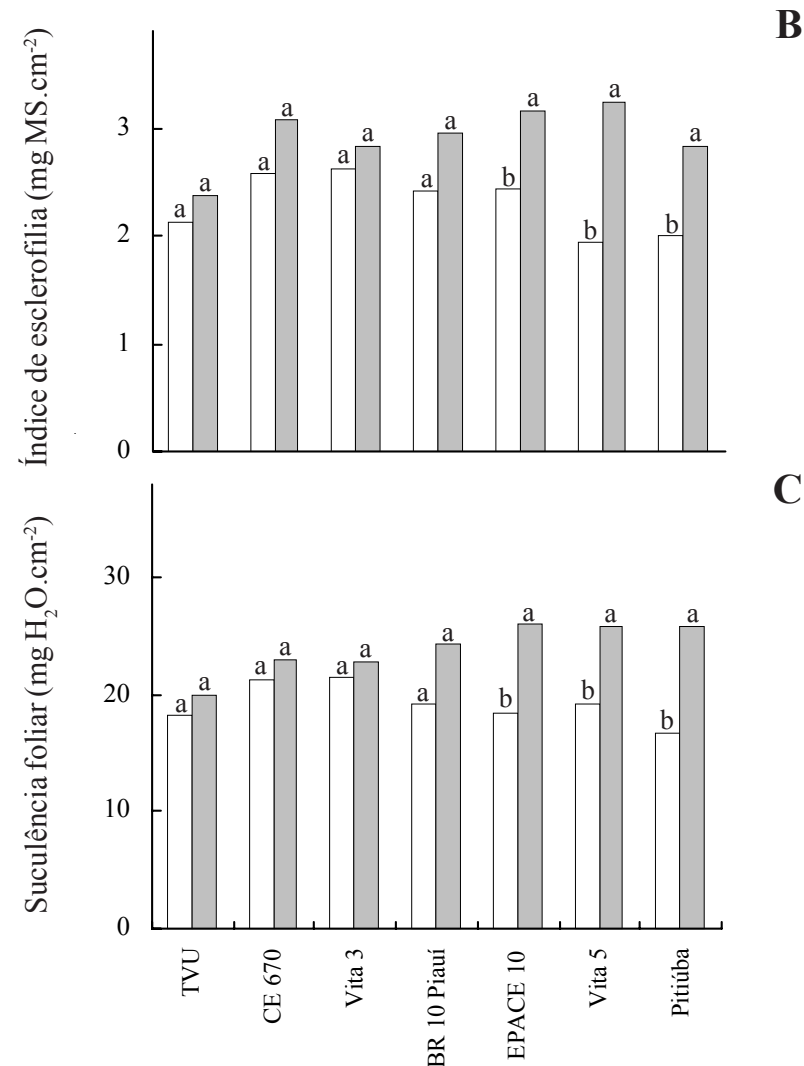

Figura 2. Área foliar (A), índice de esclerofilia (B) e suculência foliar (C) dos cultivares de feijão-de-corda submetidos aos tratamentos-controle $(\square)$ e de estresse salino ( $\square$ ). Valores com mesmas letras dentro de cada cultivar não diferem entre si pelo teste de Tukey, a 5\% de probabilidade.

Figure 2. Leaf area (A), leaf sclerophylly index (B) and leaf succulence (C) of cowpea cultivars from control ( $\square$ ) and salt stress $(\square)$ treatments. Values followed by the same letter within each cultivar do not differ statistically at 5\% probability, by Tukey's test.

Figure 1. Root (A), shoot (B) and plant (C) dry matter, and root/shoot ratio (D) of cowpea cultivars from control ( $\square$ ) and salt stress ( $\square$ ) treatments. Values followed by the same letter within each cultivar do not differ statistically at 5\% probability, by Tukey's test. 
com o Pitiúba e o Vita 5 no nível 1, enquanto no nível 3 ficaram os cultivares CE 670 e TVU. Quando a área foliar foi tomada como base, a única alteração observada ocorreu no cv. CE 670, que passou do nível 3 para o nível 2 (tabela 1).

Tabela 1. Níveis crescentes de reduções nas matérias secas da raiz, da parte aérea e total, e na área foliar, em resposta à salinidade. Níveis iguais, dentro da mesma coluna, não diferem significativamente pelo teste de Tukey, a 5\% de probabilidade.

Table 1. Increasing reduction levels in root, shoot and total dry matter, and in leaf area as a result to salt stress. Same values within the same column do not differ statistically at $5 \%$ probability, by Tukey's test.

\begin{tabular}{lcccc}
\hline Cultivares & Raiz & Parte aérea & Total & Área foliar \\
\hline Pitiúba & 1 & 1 & 1 & 1 \\
Vita 5 & 1 & 1 & 1 & 1 \\
Epace 10 & 2 & 1 & 1 & 1 \\
BR 10 Piauí & 2 & 1 & 1 & 1 \\
Vita 3 & 2 & 2 & 2 & 2 \\
CE 670 & 2 & 3 & 3 & 2 \\
TVU & 3 & 3 & 3 & 3 \\
\hline
\end{tabular}

A análise dos íons inorgânicos mostrou que, sob condições-controle, os teores de $\mathrm{Na}^{+}, \mathrm{Cl}^{-}$e $\mathrm{K}^{+}$nas folhas desenvolvidas dos cultivares estudados foram, em média, 126,401 e $2.054 \mu \mathrm{mol} . \mathrm{g}^{-1} \mathrm{MS}$, respectivamente (tabela 2), não sendo, contudo, observadas diferenças significativas com relação aos teores de $\mathrm{Na}^{+}$ou de $\mathrm{Cl}^{-}$entre os vários cultivares estudados. Em resposta à salinidade, todos os cultivares aumentaram de forma significativa os teores de $\mathrm{Na}^{+}$, sendo o TVU aquele que mais acumulou este íon, com um aumento em relação ao das plantas-controle de $1.258 \%$, enquanto o Epace 10 foi o que apresentou menor aumento (331\%). De forma idêntica, todos os cultivares acumularam $\mathrm{Cl}^{-}$em resposta à salinidade, sendo o maior aumento observado no Vita $5(412 \%)$ e o menor no TVU (175\%). Com relação aos teores de $\mathrm{K}^{+}$, a resposta ao estresse foi variada, tendo os cultivares Vita 3 e Pitiúba apresentado reduções (34,6\% e 19,7\%, respectivamente); CE 670 e BR 10 Piauí, aumentos $(74,1 \%$ e $33,2 \%$, respectivamente) e o restante não apresentou alterações significativas em relação às plantas-controle. $\mathrm{O}$ estresse salino, com exceção para os cultivares BR 10 Piauí e Epace 10, aumentou significativamente a relação $\mathrm{Na}^{+} / \mathrm{K}^{+}$, sendo os maiores aumentos observados no TVU e Vita 3 , superiores a $1.500 \%$ (tabela 2).
Nas folhas em início de desenvolvimento, os teores de $\mathrm{Na}^{+}, \mathrm{Cl}^{-}$e $\mathrm{K}^{+}$das plantas cultivadas em condiçõescontrole foram, em média, 112,427 e $1.140 \mu \mathrm{mol} . \mathrm{g}^{-1}$ MS, respectivamente (tabela 2). Os níveis de $\mathrm{Na}^{+}$ aumentaram significativamente, em função da salinidade, apenas nos cultivares TVU $(83,6 \%)$, CE 670 $(105,6 \%)$ e Vita $3(92,6 \%)$ enquanto os de $\mathrm{Cl}^{-}$ aumentaram nos cultivares TVU (138\%), CE 670 (267\%), Vita $3(154 \%)$, Vita 5 (238\%) e Pitiúba $(90,6 \%)$. Os teores de $\mathrm{K}^{+}$praticamente não foram alterados pela salinidade, exceto nos cultivares TVU (aumento de 23,9\%) e Pitiúba (redução de 19,3\%). A salinidade provocou aumentos significativos na relação $\mathrm{Na}^{+} / \mathrm{K}^{+}$nos folíolos jovens dos cultivares TVU $(54,5 \%)$, Vita $5(55,5 \%)$, CE $670(100 \%)$ e Vita $3(109 \%)$ (tabela 2).

Os teores de prolina e $\mathrm{N}$-aminossolúveis em extremidades de raízes dos cultivares estudados não foram significativamente alterados pela salinidade no meio de cultivo (figura 3A, B), enquanto os níveis de carboidratos solúveis foram significativamente reduzidos pela salinidade nos cultivares Pitiúba (41,3\%), Vita $3(55,3 \%)$ e TVU (56,3\%) (figura 3C).

Nas folhas em início de desenvolvimento, os teores de prolina nos cultivares estudados não foram significativamente alterados pela salinidade, exceto no CE 670, no qual se observou um aumento de $386 \%$ (figura 4A). A salinidade aumentou o teor de Naminossolúvel no cultivar TVU (50,0\%), enquanto nos demais não foram observadas alterações significativas (figura 4B). O teor de carboidratos solúveis não foi alterado pela salinidade nos cultivares em estudo, à exceção do Vita 5 (figura 4C).

Os teores de proteínas solúveis, determinados nas folhas em início de desenvolvimento e nas extremidades de raízes, variaram entre 60,0 a 72,7 e 41,9 a 77,8 mg.g ${ }^{-1}$ MS, respectivamente, não sendo observadas diferenças estatísticas significativas entre os tratamentos controle e salino (resultados não apresentados).

\section{Discussão}

A salinidade reduziu o crescimento de todos os cultivares de feijão-de-corda estudados, sendo a parte aérea mais afetada que as raízes (figura 1). $\mathrm{O}$ cultivar TVU apresentou as maiores reduções na matéria seca e área foliar (figura 2A). Embora a classificação com base nos parâmetros de crescimento tenha sofrido algumas variações em função do parâmetro analisado, os cultivares Pitiúba e Vita 5 se apresentaram sempre como os mais tolerantes (nível 1), o Vita 3 como o de tolerância 
Tabela 2. Teores de $\mathrm{Na}^{+}, \mathrm{Cl}^{-}$e $\mathrm{K}^{+}\left(\mu \mathrm{mol} \cdot \mathrm{g}^{-1} \mathrm{MS}\right)$ e relação $\mathrm{Na}^{+} / \mathrm{K}^{+}$nas folhas desenvolvidas e em início de desenvolvimento dos cultivares de feijão-de-corda, sob condições-controle (C) e de estresse salino (E). Médias dentro da mesma coluna, para cultivares, seguidas da mesma letra, não diferem entre si pelo teste de Tukey, a 5\% de probabilidade.

Table 2. Contents of $\mathrm{Na}^{+}, \mathrm{Cl}^{-}$and $\mathrm{K}^{+}\left(\mu \mathrm{mol} \cdot \mathrm{g}^{-1} \mathrm{MS}\right)$, and $\mathrm{Na}^{+} / \mathrm{K}^{+}$ratio in mature and young expanding leaves of cowpea cultivars from control (C) and salt stressed (E) plants. Mean values followed by the same letter within the same column do not differ statistically at $5 \%$ probability, by Tukey's test.

\begin{tabular}{|c|c|c|c|c|c|c|c|c|}
\hline \multirow[t]{2}{*}{ Cultivares } & \multicolumn{2}{|c|}{$\mathrm{Na}^{+}$} & \multicolumn{2}{|r|}{$\mathrm{Cl}^{-}$} & \multicolumn{2}{|c|}{$\mathrm{K}^{+}$} & \multicolumn{2}{|c|}{$\mathrm{Na}^{+} / \mathrm{K}^{+}$} \\
\hline & $\mathrm{C}$ & E & $\mathrm{C}$ & E & $\mathrm{C}$ & E & $\mathrm{C}$ & $\mathrm{E}$ \\
\hline \multicolumn{9}{|c|}{ Folhas desenvolvidas } \\
\hline TVU & 119 e & $1616 \mathrm{a}$ & $457 \mathrm{e}$ & $1256 \mathrm{bcd}$ & $2186 \mathrm{bcd}$ & $1801 \mathrm{cde}$ & $0,05 \mathrm{f}$ & $0,89 \mathrm{a}$ \\
\hline CE 670 & $116 \mathrm{e}$ & $902 \mathrm{bcd}$ & $324 \mathrm{e}$ & $1031 \mathrm{~d}$ & $920 \mathrm{~g}$ & 1602 ef & $0,13 \mathrm{def}$ & $0,57 \mathrm{~b}$ \\
\hline Vita 3 & $111 \mathrm{e}$ & $1147 \mathrm{~b}$ & $474 \mathrm{e}$ & $1756 \mathrm{a}$ & 1814 cde & $1186 \mathrm{fg}$ & $0,06 \mathrm{f}$ & $0,98 \mathrm{a}$ \\
\hline BR10 Piauí & $111 \mathrm{e}$ & $757 \mathrm{~cd}$ & 317 e & $1057 \mathrm{~cd}$ & $1731 \mathrm{de}$ & $2306 \mathrm{abc}$ & 0,07 ef & 0,33 bcde \\
\hline Epace 10 & $139 \mathrm{e}$ & 599 d & $493 \mathrm{e}$ & $1579 \mathrm{ab}$ & $2198 \mathrm{bcd}$ & $2506 \mathrm{ab}$ & 0,07 ef & 0,24 cdef \\
\hline Vita 5 & $151 \mathrm{e}$ & $977 \mathrm{bc}$ & $270 \mathrm{e}$ & $1383 \mathrm{abcd}$ & $2716 \mathrm{ab}$ & $2353 \mathrm{ab}$ & $0,06 \mathrm{f}$ & $0,42 \mathrm{bc}$ \\
\hline Pitiúba & $130 \mathrm{e}$ & $784 \mathrm{~cd}$ & 472 e & $1439 a b c$ & $2815 \mathrm{a}$ & $2261 \mathrm{bcd}$ & $0,04 \mathrm{f}$ & $0,35 \mathrm{bcd}$ \\
\hline \multicolumn{9}{|c|}{ Folhas em início de desenvolvimento } \\
\hline TVU & $116 \mathrm{bc}$ & $213 \mathrm{a}$ & $596 \mathrm{de}$ & 1419 a & $1025 \mathrm{~d}$ & $1270 \mathrm{ab}$ & $0,11 \mathrm{~cd}$ & $0,17 \mathrm{~b}$ \\
\hline CE 670 & $125 \mathrm{bc}$ & $257 \mathrm{a}$ & 467 def & $1715 \mathrm{a}$ & $1113 \mathrm{bcd}$ & $1181 \mathrm{abcd}$ & $0,11 \mathrm{~cd}$ & $0,22 \mathrm{a}$ \\
\hline Vita 3 & $122 \mathrm{bc}$ & $235 \mathrm{a}$ & 387 def & $983 \mathrm{bc}$ & $1077 \mathrm{bcd}$ & $1014 \mathrm{~d}$ & $0,11 \mathrm{~cd}$ & $0,23 \mathrm{a}$ \\
\hline BR10 Piauí & $99 \mathrm{c}$ & $105 \mathrm{c}$ & 352 ef & $581 \mathrm{de}$ & $1056 \mathrm{~cd}$ & $1077 \mathrm{bcd}$ & $0,09 \mathrm{~d}$ & $0,10 \mathrm{~cd}$ \\
\hline Epace 10 & $95 \mathrm{c}$ & $95 \mathrm{c}$ & 426 def & $616 \mathrm{de}$ & $1103 \mathrm{bcd}$ & $1019 \mathrm{~d}$ & $0,09 \mathrm{~d}$ & $0,09 \mathrm{~d}$ \\
\hline Vita 5 & $119 \mathrm{bc}$ & $160 \mathrm{~b}$ & $208 \mathrm{f}$ & $703 \mathrm{~cd}$ & $1249 \mathrm{abc}$ & $1129 \mathrm{bcd}$ & $0,09 \mathrm{~d}$ & $0,14 \mathrm{bc}$ \\
\hline Pitiúba & $110 \mathrm{bc}$ & $109 \mathrm{c}$ & $551 \mathrm{def}$ & $1050 \mathrm{~b}$ & $1354 \mathrm{a}$ & $1093 \mathrm{bcd}$ & $0,08 \mathrm{~d}$ & $0,10 \mathrm{~cd}$ \\
\hline
\end{tabular}

intermediária (nível 2) e o cultivar TVU como o menos tolerante à salinidade (nível 3) (tabela 1), demonstrando que há diferenças entre os cultivares estudados com relação ao grau de tolerância à salinidade.

Embora a relação raiz/parte aérea seja utilizada como critério para classificação de cultivares quanto a tolerância aos estresses hídrico e salino (Kramer 1983, Lutts et al. 1996), os resultados aqui apresentados mostram que aquele parâmetro não discriminou de maneira eficiente os cultivares, uma vez que os que se mostraram mais sensíveis à salinidade, ou com sensibilidades intermediárias (TVU, CE-670 e Vita 3), foram os cultivares que apresentaram maiores aumentos naquela relação (figura 1D). Essa discrepância pode ser explicada pelo fato de que os maiores aumentos na relação raiz/parte aérea se deram em função de decréscimos mais acentuados na produção de matéria seca da parte aérea em resposta ao estresse salino, e não a um aumento no crescimento do sistema radicular dessas plantas.

Os maiores aumentos nos índices de esclerofilia e de suculência foliar nos cultivares Vita 5 e Pitiúba (figura
2B, C), os mais tolerantes, é uma das modificações mais facilmente visualizada nas glicófitas sob estresse salino (Greenway \& Munns 1980) e sugerem uma resposta adaptativa desses cultivares à salinidade. Embora o aumento no índice de esclerofilia seja interpretado por alguns autores como resultante de um maior espessamento da parede das células do mesofilo (Shannon et al. 1994), em função de alterações na síntese de parede celular (Fricke \& Peters 2002), nos cultivares de feijão-de-corda mais tolerantes à salinidade ocorreu aumento simultâneo dos índices de esclerofilia e de suculência, resultado, possívelmente, de um aumento no volume das células do mesofilo esponjoso em detrimento ao volume das células do parênquima paliçádico, fato observado em Phaseolus vulgaris por Wigharajah et al. (1975).

Os grandes aumentos nos teores foliares de $\mathrm{Na}^{+}$ e de $\mathrm{Cl}^{-}$provocados pela salinidade (tabela 2 ) possivelmente causaram toxidez (Niu et al. 1995, Munns 2002) e podem ter se constituido num fator importante para a redução no crescimento. $\mathrm{O}$ maior acúmulo de $\mathrm{Na}^{+}$ocorreu justamente no cultivar mais sensível, o TVU, 
enquanto que os menores aumentos ocorreram no Epace 10, Vita 5 e Pitiúba, os dois últimos os mais tolerantes. Embora o $\mathrm{Na}^{+}$em alta concentração possa substituir o $\mathrm{Ca}^{2+}$ presente nas membranas celulares (Cramer et al. 1985), e daí causar danos em sua integridade, provocando vazamento de íons (principalmente de $\mathrm{K}^{+}$) e de solutos orgânicos (Blis et al. 1984, Bem-Hayyim et al. 1987), isso parece não ter acontecido com as plantas em estudo. Como mostrado na tabela 2, a salinidade não reduziu de forma significativa o teor de $\mathrm{K}^{+}$nas folhas do cultivar TVU, apesar de o mesmo ter sido o que mais tenha acumulado $\mathrm{Na}^{+}$em suas folhas. $\mathrm{O}$ fato de os teores de $\mathrm{K}^{+}$, mesmo em condições salinas, ter sido muito superior aos de $\mathrm{Na}^{+}$, demonstra a alta capacidade das folhas dos cultivares de feijão-de-corda em acumular aquele íon. Apesar disso, não parece, contudo, ter o $\mathrm{K}^{+}$papel importante no ajustamento osmótico das folhas dos cultivares de feijão-de-corda estudados. $\mathrm{O}$ aumento na relação $\mathrm{Na}^{+} / \mathrm{K}^{+}$foi maior no TVU, cultivar mais sensível ao estresse salino (tabela 2), e pode ter contribuído para a grande redução no crescimento da parte aérea deste cultivar, desde que aumentos nessa relação podem causar inativação de enzimas e inibição da síntese protéica (Greenway \& Osmond 1972, Flowers et al. 1977). Em concordância com a afirmação de McKersie \& Leshem (1994), a análise dos resultados sugerem que o $\mathrm{Cl}^{-}$, em condições de salinidade, seja translocado das raízes para a parte aérea de forma mais rápida que $\mathrm{o} \mathrm{Na}^{+}$, pois nas folhas em início de desenvolvimento o aumento médio no teor de $\mathrm{Cl}^{-}$está muito próximo daquele medido nas folhas desenvolvidas, diferentemente do que ocorreu com o $\mathrm{Na}^{+}$.

$\mathrm{O}$ fato de prolina e $\mathrm{N}$-aminossolúvel não se terem acumulado nas extremidades de raízes dos cultivares de feijão-de-corda estudados (figura 3A, B), sugere que esses osmólitos não contribuam para o ajustamento osmótico naqueles tecidos. De forma idêntica, nas folhas em início de desenvolvimento, em geral, não se observaram diferenças significativas nos teores desses osmólitos provocadas pela salinidade (figura 4A, B). $\mathrm{O}$ grande aumento, devido à salinidade, no teor de prolina das folhas em início de desenvolvimento do cultivar CE 670 provavelmente não ocorreu em função de hidrólise de proteínas, pois tanto os teores de $\mathrm{N}$ aminossolúveis (figura 4B) e de concentração de proteínas (resultados não apresentados) não sofreram alterações significativas. Aumentos nos níveis de prolina em tecidos submetidos a estresse salino têm sido atribuidos, pelo menos em parte, ao aumento na expressão da sintetase da $\Delta^{1}$-pirrolino-5-carbobxilato,

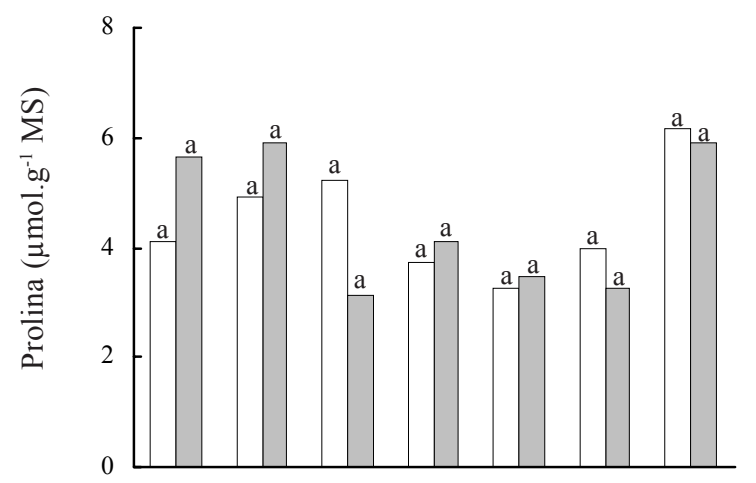

A

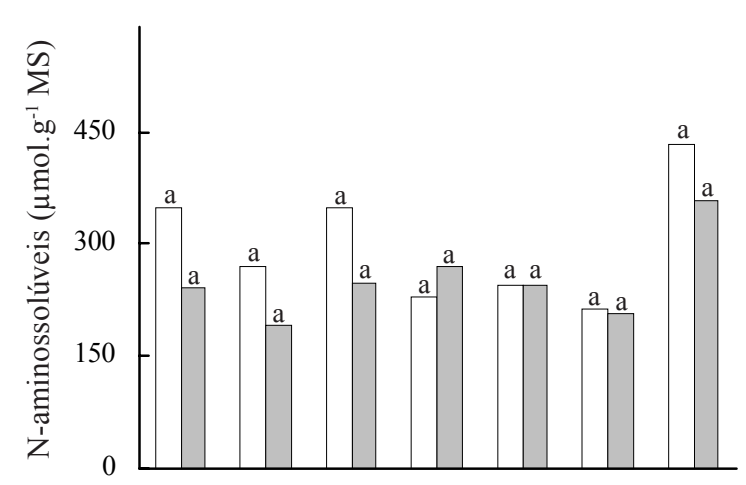

B

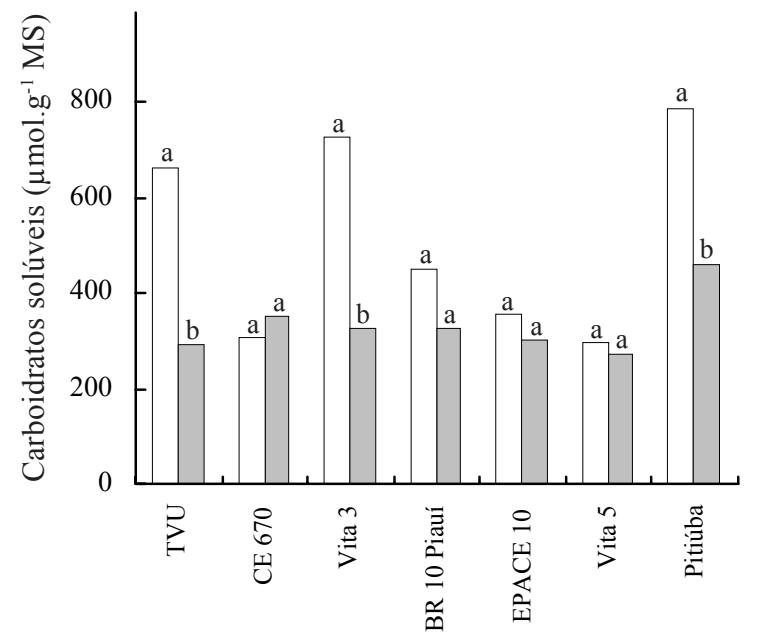

Figura 3. Teores de prolina (A), N-aminossolúveis (B) e carboidratos solúveis $(\mathrm{C})$ nas extremidades de raízes dos cultivares de feijão-de-corda submetidos aos tratamentoscontrole ( $\square$ ) e de estresse salino ( $\square$ ). Valores com mesmas letras dentro de cada cultivar não diferem entre si pelo teste de Tukey, a $5 \%$ de probabilidade.

Figure 3. Proline (A), soluble amino-N (B) and soluble carbohydrate $(\mathrm{C})$ contents in root tips of cowpea cultivars from control $(\square)$ and salt stress $(\square)$ treatments. Values followed by the same letter within each cultivar do not differ statistically at $5 \%$ probability, by Tukey's test. 

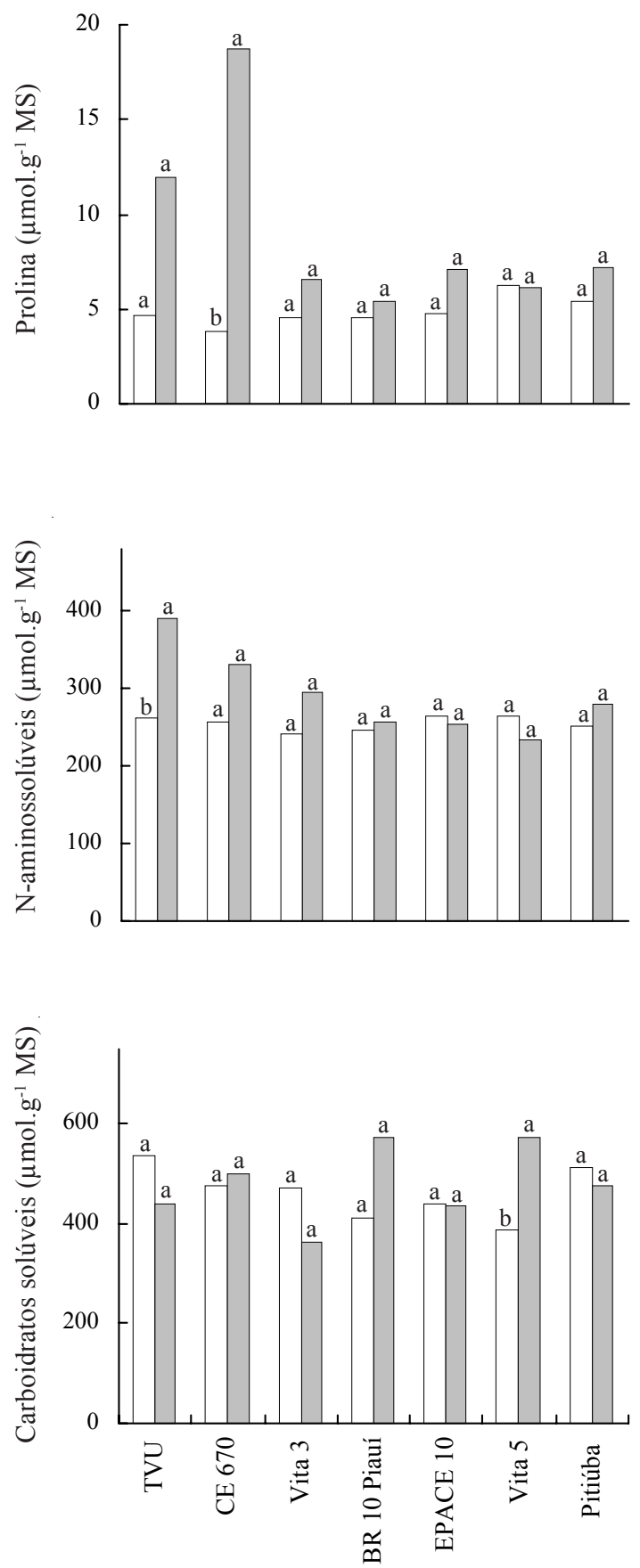

Figura 4. Teores de prolina (A), N-aminossolúveis (B) e carboidratos solúveis (C) nas folhas em início de desenvolvimento dos cultivares de feijão-de-corda submetidos aos tratamentos-controle $(\square)$ e de estresse salino (匹). Valores com mesmas letras dentro de cada cultivar não diferem entre si pelo teste de Tukey, a 5\% de probabilidade.

Figure 4. Proline (A), soluble amino-N (B) and soluble carbohydrate $(\mathrm{C})$ contents in young leaves of cowpea cultivars from control $(\square)$ and salt stress $(\square)$ treatments. Values followed by the same letter within each cultivar do not differ statistically at $5 \%$ probability, by Tukey's test.

A enzima-chave na via biossintética da prolina (Liu \& Zhu 1997).

Os efeitos da salinidade sobre os níveis de carboidratos solúveis em extremidades de raízes (figura 3C) sugerem que esses osmólitos não contribuíram para o ajustamento osmótico das plantas. Nos cultivares Vita 5, Epace 10 e CE 670, as diferenças entre os tratamentos controle e salino não foram significativas, enquanto nos cultivares Pitiúba, Vita 3 e TVU, respectivamente, o mais tolerante, o de tolerância intermediária e o mais sensível, foram observadas reduções quase semelhantes. De forma idêntica, tal ajustamento osmótico também não ocorreu nas folhas em início de desenvolvimento (figura 4C), pois, com exceção do Vita 5, que apresentou aumento no teor de carboidratos solúveis, não houve alterações significativas nos teores desses osmólitos. Estes resultados diferem dos observados por Franco et al. (1999), que, trabalhando com os cultivares de feijão-de-corda Vita 3 e Vita 5 em fase de estabelecimento da plântula (sete dias após a semeadura), observaram um aumento nos teores de carboidratos solúveis em extremidades de raízes do Vita 3 , e uma redução em Vita 5, devido à salinidade.

Pode-se concluir que, apesar de todos os cultivares terem acumulado grandes quantidades de $\mathrm{Na}^{+}$nas folhas em resposta à salinidade, os mais sensíveis foram os que mais acumularam esse íon. A suculência foliar e o índice de esclerofilia apresentaram proporcionalidade com o grau de tolerância, aumentando significativamente, em função da salinidade apenas nos cultivares mais tolerantes. Embora os solutos orgânicos estudados, principalmente carboidratos solúveis e $\mathrm{N}$-aminossolúveis, que se apresentaram em teores muito mais elevados que os de prolina, possam contribuir para a manutenção de um potencial hídrico favorável à absorção de água, os mesmos não apresentaram proporcionalidade entre seus teores e o grau de tolerância à salinidade.

Agradecimentos - Os autores são gratos ao $\mathrm{CNPq}$, Capes e Funcap pelos auxílios financeiros.

\section{Referências bibliográficas}

APSE, M.P., AHARON, G.S., SNEDDEN, W.A. \& BLUMWALD, E. 1999. Salt tolerance conferred by overexpression of a vacuolar $\mathrm{Na}^{+} / \mathrm{H}^{+}$antiport in Arabidopsis thaliana. Science 285:1256-1258.

BATES, L.S., WALDREN, R.P. \& TEARE, J.D. 1973. Rapid determination of free proline for water-stress studies. Plant and Soil 39:205-207. 
BEN-HAYYIM, G., KAFKAFI, U. \& GANMORE-NEWMAN, R. 1987. The role of internal potassium in maintaining growth of cultured Citrus cells on increasing $\mathrm{NaCl}$ and $\mathrm{CaCl}_{2}$ concentration. Plant Physiology 85:434-439.

BLIS, R.D., PLATT-ALOIA, K.A. \& THOMSON, W.N. 1984. Changes in plasmalema organization in cowpea radicule during inhibition in water and $\mathrm{NaCl}$ solutions. Plant, Cell \& Environment 7:601-606.

BOHNERT, H.J. \& SHEN, B. 1999. Transformation and compatible solutes. Scientia Horticulturae 78:237-260.

BRADFORD, M.M. 1976. A rapid and sensitive method for the quantitation of microgram quantities of protein utilizing the principle of dye binding. Analytical Biochemistry 72:248-254.

COCKING, E.C. \& YEMM, E.W. 1954. Estimation of aminoacids by ninhidrin. The Biochemical Journal 58:12-13.

CRAMER, G.R., LAUCHLI, A. \& POLITO, V.L. 1985. Displacement of $\mathrm{Ca}^{2+}$ by $\mathrm{Na}^{+}$from the plasmalemma of root cells. A primary response to salt stress? Plant Physiology 79:207-211.

DUBOIS, M., GILLES, K.A. HAMILTON, J.K., REBERS, P.A. \& SMITH, F. 1956. Colorimetric method for determination of sugars and related substances. Analytical Chemistry 28:350-356.

EPSTEIN, E. 1975. Nutrição mineral de plantas: princípios e perspectivas. Edusp, São Paulo.

FAO. 2000. Global network on integrated soil management for sustainable use of salt-affected soils. 2000. Disponível em: http://www.fao.org/ag/AGL/agll/spush/ intro.htm. Acesso em 10 de maio de 2002.

FLOWERS, T.J., TROKE, P.F. \& YEO, A.R. 1977. The mechanism of salt tolerance in halophytes. Annual Review of Plant Physiology 28:89-121.

FRANCO, O.L., ENÉAS FILHO, J., PRISCO, J.T. \& GOMES FILHO, E. 1999. Effects of $\mathrm{CaCl}_{2}$ on growth and osmoregulator accumulation in $\mathrm{NaCl}$ stressed cowpea seedlings. Revista Brasileira de Fisiologia Vegetal 11:145-151.

FRICKE, W. \& PETERS, W.S. 2002. The biophysics of leaf growth in salt-stressed barley. A study at the cell level. Plant Physiology 129:374-388.

GAINES, T.P., PARKER, M.B. \& GASCHO, G.J. 1984. Automated determination of chorides in soil and plant tissues by sodium nitrate. Agronomy Journal 76:371-374.

GREENWAY, H. \& OSMOND, C.B. 1972. Salt responses of enzymes from species differing in salt tolerance. Plant Physiology 49:256-259.

GREENWAY, H. \& MUNNS, R. 1980. Mechanisms of salt tolerance in nonhalophytes. Annual Review of Plant Physiology 31:149-190.

HOPKINS, G.W. 1999. Introduction to plant physiology. John Wiley \& Sons, New York.

KRAMER, P.J. 1983. Water relations of plants. Academic Press, New York.
LEVITT, J. 1980. Response of plants to environmental stresses. Water, radiation, salt, and other stress. $2^{\text {nd }}$ ed. Academic Press, New York, v. 2.

LIU, J. \& ZHU, J.-K. 1997. Proline accumulation and saltstress-induced gene expression in a salt-hypersensitive mutant of Arabidopsis. Plant Physiology 114:591-596.

LUTTS, S., KINET, J.M. \& BOUHARMONT, J. 1996. Effects of salt stress on growth, mineral nutrition and proline accumulation in relation to osmotic adjustment in rice (Oryza sativa L.) cultivars differing in salinity resistance. Annals of Botany 78:389-398.

MALAVOLTA, E., VITTI, G.C. \& OLIVEIRA, S.A. 1989. Avaliação do estado nutricional das plantas: princípios e aplicações. Associação Brasileira para Pesquisa da Potassa e do Fosfato, Piracicaba.

MCKERSIE, B.B. \& LESHEM, Y.Y. 1994. Stress and stress copin in cultivated plants. Kluwer Academic Publisher, London.

MUNNS, R. 2002. Comparative physiology of salt and water stress. Plant, Cell \& Environment 28:239-250.

NIU, X., BRESSAN, R.A., HASEGAWA, P.M. \& PARDO, J.M. 1995. Ion homeostasis in $\mathrm{NaCl}$ stress environments. Plant Physiology 109:735-742.

NOBLE, C.L. \& ROGERS, M.E. 1992. Arguments for the use of physiological criteria for improving the salt tolerance in crops. Plant Soil 146:99-107.

O'LEARY, J.W. 1995. Adaptive components of tolerance. In Handbook of plant and crop physiology (M. Pessarakli, ed.). Marcel Dekker, New York, p.577-585.

PRISCO, J.T. \& VIEIRA, G.H.F. 1976. Effects of NaCl salinity on nitrogenous compounds and proteases during germination of Vigna sinensis seeds. Physiologia Plantarum 36:317-320.

RODHES, D. \& HANSON, A.D. 1993. Quaternary ammonium and tertiary sulfonium compounds in higher plants. Annual Review of Plant Physiology and Plant Molecular Biology 44:357-384.

SHANNON, M.C. 1992. The effects of salinity on cellular and biochemical processes associated with salt tolerance in tropical plants. In Proceedings in plant stress in the tropical environment (T.L. Davenport \& H.M. Harrington, eds.). University of Florida, KailuKona, p.56-63.

SHANNON, M.C., GRIEVE, C.M. \& FRANCOIS, L.E. 1994. Whole-plant response to salinity. In Plant-environmental interactions (R.E. Wilkinson, ed.). Marcel-Dekker, New York, p.199-244.

TROSSATT, C., RATHINASABAPATHI, B., WERETILNYK, A., SHEN, T., HUANG, Z., GAGE, D.A. \& HANSON, A.D. 1998. Salinity promotes accumulation of 3-dimethylsulfoniopropionate and its precursor $S$-Methylmethionine in chloroplasts. Plant Phisiology 116:165-171.

WIGHARAJAH, K., JENNINGS, D.H. \& HANDLEY, J.F. 1975. The effect of salinity on growth of Phaseolus vulgaris L. I. Anatomical changes in the first trifoliate leaf. Annals of Botany 39:1029-1038. 
